\title{
The use of plastic cover sheaths at the time of artificial insemination improved fertility of lactating dairy cows
}

\author{
S. Bas, A. Hoet, P. Rajala-Schultz, D. Sanders, and G. M. Schuenemann' \\ Department of Veterinary Preventive Medicine, The Ohio State University, Columbus 43210
}

\begin{abstract}
An adequate and clean artificial insemination (AI) technique is recommended to improve reproductive outcomes in dairy cattle. The objective of this study was to evaluate the effectiveness of using protective plastic sheaths (PS) to minimize contamination of the AI catheter (AIC) on pregnancies per AI (PAI) in lactating dairy cattle. Lactating cows housed in freestall barns on a commercial dairy farm were presynchronized with 2 injections of $\mathrm{PGF}_{2 \alpha}$ given $14 \mathrm{~d}$ apart (starting at $26 \pm 3$ d postpartum) followed by Ovsynch (GnRH-7 d-PGF ${ }_{2 \alpha}-56$ h-GnRH-16 h-timed-AI; TAI) 12 d later. Cows presenting signs of standing heat any time during the protocol received AI, whereas the remaining animals were subjected to TAI $16 \mathrm{~h}$ after second Ovsynch GnRH. At the time of AI (1 AI technician), 996 services from 773 lactating dairy cows were randomly assigned to 1 of the 2 groups; with (TRT, $\mathrm{n}=487$ ) or without $(\mathrm{CON}, \mathrm{n}=509)$ the use of disposable PS. In the TRT group, the AIC protected with a PS was introduced into the vagina; once in the cranial portion of the vagina adjacent to the cervical os, the PS was pulled back and only the AIC was manipulated through the cervix into the uterine body for semen deposition. In the CON group, cows were inseminated without the use of PS. Samples were taken with a sterile cotton swab from the tip of the AIC $(\mathrm{n}=51)$ after AI from both treatment groups. Pregnancy diagnosis was determined by ultrasonography $39 \pm 3 \mathrm{~d}$ after AI. Cultured swab samples revealed that the use of PS was effective in minimizing contamination of the AIC (positive bacterial growth: $\mathrm{TRT}=61.53 \%$ vs. $\mathrm{CON}=100 \%)$. Overall, the proportion of cows pregnant was greater for cows in TRT (42.7) compared with the CON group (36.1). For first services postpartum, PAI did not differ between CON $(43.01 \%, \mathrm{n}=194)$ and TRT $(43.8 \%, \mathrm{n}=182)$ groups. However, PAI for second or greater services were greater in TRT $(43.8 \%, \mathrm{n}=305)$ than in CON cows $(32.3 \%$, $\mathrm{n}=315)$. Results from this study provided evidence
\end{abstract}

Received August 9, 2010.

Accepted November 3, 2010.

${ }^{1}$ Corresponding author: schuenemann.5@osu.edu that the use of PS during AI improved PAI for second or greater services in lactating dairy cows. Performing a clean AI technique through the use of PS may be an effective strategy to improve reproductive outcomes in dairy cattle.

Key words: artificial insemination technique, dairy cow fertility, vaginal contaminant

\section{INTRODUCTION}

Artificial insemination is the most common breeding practice for dairy cattle in the United States (Caraviello et al., 2006; USDA, 2009). Efficient detection of estrus, timing of AI, optimal semen quality, appropriate hygienic procedures, and healthy uterine environment are key components for excellent fertility in dairy herds. This study focuses on the use of disposable, protective plastic sheaths (PS) at the time of AI as a way to minimize vaginal contamination of the AI catheter (AIC) and its potential effect on fertility. The relative importance of vaginal contaminants that may be introduced into the uterus of lactating dairy cows at the time of AI and the subsequent fertility remains unclear.

It has been shown that the presence of semen in the uterine lumen triggers a local immune response characterized by a neutrophil influx to the female reproductive tract (Zerbe et al., 2003; Troedsson, 2006; Schuberth et al., 2008). This physiological immune reaction has been described in a wide variety of species (i.e., sows, mares and mice) and has been referred to as postmating inflammatory response (Schuberth et al., 2008). In mares, this inflammatory response rises until it peaks between 6 and $12 \mathrm{~h}$ postmating; under normal conditions, the inflammatory products are cleared out of the uterus within 48 h (Katila et al., 1996). However, during AI, not only semen but also bacteria and debris may be introduced into the lumen of the uterus. Consequently, this inflammatory response of the female reproductive tract may lead to a persistent postbreeding endometritis with major negative consequences in the mare's ability to conceive (Maischberger et al., 2008). In the bovine, this physiological response appears to be weak when compared with other species (Zerbe, 2006). In a recent study, uterine cytology samples from lactating 
dairy cows were collected $4 \mathrm{~h}$ after AI for determination of polymorphonuclear cells (PMN) as an indicator of postbreeding subclinical endometritis (Kaufmann et al., 2009). This study showed that lactating dairy cows with a higher proportion of uterine PMN $4 \mathrm{~h}$ post-AI resulted in lower conception rates (Kaufmann et al., 2009).

A clean and strict protocol-driven AI technique is recommended to maximize reproductive outcomes (King et al., 1984). A possible approach for a clean AI technique may be the use of protective PS to avoid vaginal contamination of the AIC during the AI procedure. Previous studies reported no improvement on conception to first services in dairy cattle (King et al., 1984; Richards et al., 1984) when using a protective PS to avoid vaginal contamination of the AIC as opposed to no protection. Although these studies evaluated conception to first services, no data are available on fertility to second or greater services. Additionally, the potential detrimental effects of introduced bacteria (from vaginal origin) at the time of $\mathrm{AI}$ and the subsequent reproductive performance on dairy cattle need further investigation. Therefore, the objectives of this study were (1) to evaluate the effectiveness of using disposable, protective PS to minimize vaginal contamination of the AIC at the time of AI, and (2) to assess pregnancies per AI (PAI) in lactating dairy cows inseminated with or without the use of disposable protective PS. We hypothesize that the use of protective PS (clean AI technique) would minimize vaginal contamination of the AIC and improve PAI in lactating dairy cows.

\section{MATERIALS AND METHODS}

\section{Animals, Facilities, and Feeding}

A total of 1,014 services (all performed by one AI technician) from 791 lactating Holstein dairy cows (601 primiparous and 190 multiparous) in 1 commercial dairy farm were enrolled in a field trial to investigate the effectiveness of disposable protective PS (Continental Plastic Inc., Delavan, WI) at the time of AI. Briefly, cows were housed in freestall barns and milked thrice daily at approximately 8 -h intervals. The average herd rolling milk yield was 10,262 $\mathrm{kg}$, and the reported voluntary waiting period was $60 \mathrm{~d}$. Cows were fed twice daily, in the morning and afternoon, with a TMR formulated to meet or exceed dietary nutritional requirements for lactating dairy cows (NRC, 2001). This study was conducted from April to June 2009. The procedures described below were approved by The
Ohio State University Veterinary Teaching Hospital Clinical Research Advisory Committee.

\section{Breeding Management and Treatments}

For first postpartum services, cows were presynchronized with 2 injections of $\mathrm{PGF}_{2 \alpha}$ (25 mg; Lutalyse, Pfizer Animal Health, New York, NY) given 14 d apart at $26 \pm 3$ and $40 \pm 3 \mathrm{~d}$ postpartum. Twelve days after the second injection of $\mathrm{PGF}_{2 \alpha}$, all cows initiated Ovsynch (OV; Pursley et al., 1995; Brusveen et al., 2008). The initial GnRH dose (100 $\mu \mathrm{g}$; Cystorelin, Merial, Duluth, GA) of OV was followed $7 \mathrm{~d}$ later by an injection of $\mathrm{PGF}_{2 \alpha}$ and $56 \mathrm{~h}$ later, cows received the second dose of GnRH followed by timed AI (TAI; $72 \mathrm{~h}$ after the $\mathrm{PGF}_{2 \alpha}$ injection). Following the first GnRH of $\mathrm{OV}$, estrus was detected by visual observation plus tail chalking once daily, and all animals presenting visual signs of standing estrous behavior (cows staying still when mounted or presenting rubbed off tail chalking) received AI. Animals that did not display estrous behavior during the synchronization protocol were subjected to TAI $72 \mathrm{~h}$ after the $\mathrm{PGF}_{2 \alpha}$ injection of OV. Cows that were previously inseminated, but showed visual signs of estrous behavior before the pregnancy diagnosis were reinseminated. Additionally, open cows at the time of pregnancy diagnosis ( $39 \pm 3$ d post-AI) were re-enrolled in an OV program as described previously. Reconfirmation of pregnancy was made approximately $30 \mathrm{~d}$ after the first pregnancy diagnosis $(69 \pm 3 \mathrm{~d}$ post-AI).

Visual observation of estrous behavior (i.e., reading of tail chalk) and AI were performed by the same AI technician. At the time of AI, 1,014 services from lactating dairy cows were randomly assigned to 1 of the 2 treatment groups (alternating the use of PS on every other cow), with (TRT, $\mathrm{n}=493$ ) or without (CON, n $=521$ ) the use of protective PS as described previously. The PS device ( $30 \mathrm{~cm}$ in length $\times 0.7 \mathrm{~cm}$ in diameter) is a rigid polyvinyl chloride tube that was developed to help prevent vaginal contamination of the AI gun at the time of AI (King et al., 1984). One end, where the insemination catheter is introduced, has a funnel shape, whereas the other end is sealed with a scored rubber cap that can be easily perforated when pressure is applied. For all services performed in the TRT group, the AIC protected with a PS was introduced in the vagina; once in the cranial portion of the vagina adjacent to the cervical os, the PS was pulled back, exposing the AIC that was manipulated through the cervix into the uterine body for semen deposition. In the CON group, the AIC was introduced to the vagina without the use 
of PS and was manipulated through the cervix for deposition of the seminal dose in the uterine lumen.

\section{Bacterial Growth and Identification}

To assess the effectiveness of protective PS to minimize vaginal contamination of the AIC at the time of AI, samples from the tip of the AIC were collected with a sterile cotton swab (BD, Franklin Lakes, NJ) from a subset of cows $(\mathrm{n}=51)$ immediately after AI. At the beginning of the experiment ( 5 -wk period), cows were stratified by parity and randomly selected for collection of swab samples. It was estimated that the use of protective PS at the time of AI (TRT) would reduce positive bacterial cultures by 40 percentage points (e.g., $100 \%$ to $60 \%$ ) as opposed to AI without PS (CON); thus, 25 swabs samples from the tip of the AIC per treatment group would be needed to detect statistical significance ( $\alpha=0.05$ and $\beta=0.10$ ). Briefly, the AIC used in the CON group $(\mathrm{n}=25)$ were carefully pulled out of the reproductive tract (i.e., uterine body, cervix, vagina, and vulva), and samples were collected with sterile swabs (one swab per insemination). Prior to removal of AIC from the vagina, the vulva lips were opened to avoid contact of the AIC with the outside portion of the vulvar skin; therefore, direct contamination with manure or skin or a combination of manure and skin surface was avoided. Once outside, a sterile premoistened (in sterile saline solution) cotton swab sample was collected from the tip and distal third portion of the AI sheath covering the AIC. In the TRT group $(n=26)$, after semen deposition, the AIC was reintroduced into the PS before leaving the cervix; therefore, the AIC was covered with the PS on its transit out of the vagina (the AIC was only exposed to the cervix and uterine environment). Once outside, the PS was pulled back to expose the AIC, and sterile, premoistened cotton swab samples were collected as described previously for CON group.

Swab samples were immediately transported to the laboratory in Stuart transport media (Becton-Dickinson) at ambient temperature for further bacteriologic analysis. Once in the laboratory, swab samples were cultured onto blood (tryptic soy agar with 5\% sheep blood; Remel, Lenexa, KS) and MacConkey agar plates (Oxoid, Basingstoke, UK) for $24 \mathrm{~h}$ at $37^{\circ} \mathrm{C}$ under aerobic conditions. When colony growth was visually observed on blood agar and MacConkey plates after the incubation period, each unique colony was selected based on morphology, pigmentation, and hemolytic pattern and further purified in individual blood agar plates for genus identification. Pure isolates were then stored at $-20^{\circ} \mathrm{C}$ until final genus identification at the Diagnostic and Research Laboratory on Infectious Diseases (Columbus, $\mathrm{OH})$.

Bacterial growth density immediately after culture was assessed semiquantitatively based on the number of bacterial colonies that grew in the blood agar and MacConkey plates. Growth density was assessed on swab samples collected on wk 2 to 5 . Briefly, the proportion of growth density in each culture plate (from TRT and CON groups) was classified using the following semiquantitative scale: 1 = light or sparse growth (1-20 visible colonies located at the inoculation site); 2 $=$ moderate growth (21-100 visible colonies); and $3=$ heavy growth (over 100 visible colonies per plate or not possible to count due to heavy growth).

\section{Statistical Analyses}

Swab samples from a subset of cows $(\mathrm{n}=51)$ were collected from the tip of the AIC immediately after AI to assess the effectiveness of using disposable, protective PS to minimize vaginal contamination of the AIC. The proportion of visible colonies after culture and the proportion of bacteria isolated (from the total number of identified isolates) in the 2 treatment groups (CON or TRT) were analyzed by Proc Freq (SAS Institute Inc., 2009). A $P$-value $<0.05$ was considered statistically significant.

Prior to data analysis, enrolled lactating dairy cows that met the exclusion criteria (i.e., cows that were AI but died before the pregnancy diagnosis, cows with a history of abortion before AI, dead and sold animals) were removed from the analysis. Data were arranged in a complete randomized design. Following AI, the proportion of cows that conceived (PAI) at first and second or greater services in the 2 treatment groups (CON, $\mathrm{n}=487$ or TRT, $\mathrm{n}=509)$ were evaluated. Data pertaining to PAI were analyzed using generalized linear mixed models (Proc Glimmix; SAS Institute Inc., 2009). A model procedure that included treatment (CON or TRT), parity (primiparous or multiparous), DIM at the time of AI, sire, and SCC at the closest DHIA test relative to service was used to compare differences in PAI between treatments. Nonsignificant variables were eliminated from the logistic model 1 at a time using the Wald statistic backward selection criterion $(P>0.15)$. Week of the experimental period was included as a random effect. The estimates (proportions of PAI) from the final model were reported as least squares means (Bar et al., 2008; Tsousis et al., 2009; Pinedo and De Vries, 2010). The differences between least squares means were calculated by including the PDIFF option in the LSMEANS statement (Tsousis et al., 2009). Differences in individual least squares means 
Table 1. Distribution of services (first and second or greater services) with respect to parity (primiparous or multiparous), DIM, milk yield $(\mathrm{kg})$, and SCC in lactating dairy cows ${ }^{1}$

\begin{tabular}{|c|c|c|c|c|}
\hline \multirow[b]{2}{*}{ Item } & \multicolumn{2}{|c|}{ First service } & \multicolumn{2}{|c|}{ Second or greater services } \\
\hline & $\begin{array}{c}\text { TRT } \\
(\mathrm{n}=182)\end{array}$ & $\begin{array}{c}\text { CON } \\
(\mathrm{n}=194)\end{array}$ & $\begin{array}{c}\text { TRT } \\
(\mathrm{n}=305)\end{array}$ & $\begin{array}{c}\mathrm{CON} \\
(\mathrm{n}=315)\end{array}$ \\
\hline Parity & 1.22 & 1.29 & 1.37 & 1.31 \\
\hline DIM & 62.73 & 65.23 & 174.24 & 170.88 \\
\hline Number of services & 1 & 1 & 3.72 & 3.55 \\
\hline Milk yield (kg) & 34.5 & 34.7 & 34.6 & 33.2 \\
\hline $\operatorname{SCC}\left(\times 10^{3}\right)$ & 136.8 & 207.56 & 155.9 & 183.2 \\
\hline
\end{tabular}

${ }^{1}$ At the time of AI, 996 services from lactating dairy cows were randomly assigned to 1 of the 2 treatment groups, with (TRT, $\mathrm{n}=487)$ and without $(\mathrm{CON}, \mathrm{n}=509)$ the use of a protective plastic sheath.

were adjusted by using Tukey-Kramer method. A $P<$ 0.05 was considered statistically significant.

\section{RESULTS}

Initially, 1,014 services were performed by 1 AI technician, of which 18 cows were removed from the analysis ( 7 animals died, 8 had an abortion before AI, and 3 cows were sold). Therefore, 996 services from 773 lactating Holstein dairy cows (590 primiparous and 183 multiparous) were available for the final analysis. The distribution of cows receiving the first postpartum services and those receiving the second or greater services was stratified with respect to parity (primiparous vs. multiparous), DIM, number of services, milk production, and SCC at the closest DHIA test relative to AI (Table 1).

\section{Bacterial Growth and Identification}

The proportion of positive bacterial growth (from the 51 swabs samples collected) was greater in CON (100\%) versus TRT cows $(61.53 \%, P=0.0002$; Table 2). Additionally, $10(38.47 \%)$ of the 26 swab samples collected from the AIC in the TRT group were negative and yielded no bacterial growth. Conversely, all swab samples from the AIC in the CON group were positive for bacterial growth $(100 \%)$. Regarding the bacterial density growth, the majority $(66.67 \%$; Table 2$)$ of the samples from the TRT group had light or sparse bacterial growth compared with the CON group, in which the majority of the samples showed heavy colony growth (71.43\%; Table 2). Because bacterial growth density was measured from swabs samples collected on wk 2 to 5 , the growth densities from wk 1 were missing (4 from CON and 1 from TRT groups; Table 2). From a total of 176 bacterial isolates obtained (CON and TRT combined), $67.04 \%$ (118) were identified and reported in the present study (Table 3 ). Swab samples collected from AIC without the use of protective PS
(92 isolates) resulted in more bacteria isolated with a greater proportion of Escherichia coli compared with the TRT group (26 isolates; Table 3).

\section{Effect of PS on PAI}

Sire $(P=0.0002)$ and DIM at service $(P=0.0005)$ were significantly associated with PAI and stayed in the final model. Overall, the proportion of cows pregnant was greater $(P<0.03)$ for cows in the TRT $(42.7 \%)$ compared with cows in the CON group (36.1\%; Table 4). No differences were observed between parities. For first postpartum services, PAI did not differ $(P<0.87)$ between the CON (43.01\%) and TRT (43.8\%; Table 4) groups. However, PAI for second and greater services were greater $(P<0.007)$ in the TRT $(43.8 \%)$ than in CON group (32.3\%; Table 4). Additionally, no differences $(P=0.44)$ were observed in pregnancy losses between pregnancy diagnosis $(39 \pm 3 \mathrm{~d}$ post-AI) and reconfirmation of pregnancy $(69 \pm 3 \mathrm{~d}$ post-AI) for cows in the TRT $(8.98 \%)$ and CON (11.57\%) groups.

\section{DISCUSSION}

The primary findings of the present study are (1) the use of protective PS was effective in minimizing contamination of the AIC at the time of AI and (2) increased PAI were observed for the second or greater services in lactating dairy cows inseminated with the use of protective PS.

The effectiveness of using protective PS to minimize vaginal contamination of the AIC at the time of AI was assessed in this study. Rigid PS has been developed to protect the AIC at the time of AI from vaginal contaminants (clean AI technique) with the aim of improving reproductive outcomes in dairy cattle (Richards et al., 1984). In this study, swab samples collected from the AIC immediately after AI revealed that the use of PS was effective in minimizing contamination of the AIC compared with unprotected AIC. The use of PS reduced 
Table 2. Proportion of positive bacterial growth and density from the AI catheter (AIC) of dairy cows inseminated with (TRT) and without (CON) the use of a protective plastic sheath (PS) in blood agar and MacConkey plates

\begin{tabular}{|c|c|c|}
\hline \multirow[b]{2}{*}{ Item } & \multicolumn{2}{|c|}{ Positive cultures and growth density ${ }^{1}$} \\
\hline & TRT & $\mathrm{CON}$ \\
\hline Positive bacterial growth, \% (n/n) & $61.53(16 / 26)$ & $100(25 / 25)$ \\
\hline Light colony growth, ${ }^{2} \%(\mathrm{n} / \mathrm{n})$ & $66.66(10 / 15)$ & $19.04(4 / 21)$ \\
\hline Moderate colony growth, ${ }^{3} \%(\mathrm{n} / \mathrm{n})$ & $20(3 / 15)$ & $9.52(2 / 21)$ \\
\hline Heavy colony growth, ${ }^{4} \%(\mathrm{n} / \mathrm{n})$ & $13.33(2 / 15)$ & $71.42(15 / 21)$ \\
\hline
\end{tabular}

${ }^{1}$ Swab samples were collected from the tip of the AIC immediately after AI for further identification of bacteria from 51 lactating dairy cows, inseminated with (TRT, $n=26$ ) and without $(\mathrm{CON}, \mathrm{n}=25)$ the use of PS. Growth density = bacterial growth density (light, moderate, and heavy) immediately after culture was assessed semiquantitatively based on the number of bacterial colonies visible that grew in blood agar and MacConkey plates. In the CON group, growth density from 4 plates was not recorded. In the TRT group, growth density from 1 plate was not recorded.

${ }^{2}$ Identification of 1 to 20 visible colonies at the inoculation site.

${ }^{3}$ Identification of 21 to 100 visible colonies.

${ }^{4}$ Identification of over 100 visible colonies per plate or identification not possible to count due to heavy growth.

by almost 40 percentage points the positive bacterial cultures (clean AI technique), as well as the growth density (heavy colony growth) per plate. Regarding the bacteria isolated, swab samples from the AIC in CON cows had a greater proportion of recognized, potential, and opportunistic uterine pathogens compared with the AIC from TRT cows. Additionally, the most common bacteria isolated from the AIC immediately after AI was $E$. coli, which was identified in almost $49 \%$ of the isolates from CON cows as opposed to $35 \%$ in TRT cows. Although the potential detrimental effects of introduced bacteria into the bovine uterus at the time of

Table 3. Proportion of bacteria isolated from the AI catheter (AIC) immediately after AI in lactating dairy cows inseminated with (TRT) and without $(\mathrm{CON})$ the use of a protective plastic sheath (PS)

\begin{tabular}{lcc}
\hline & \multicolumn{2}{c}{ Identified isolates (\%) over total $(\mathrm{n} / \mathrm{n})^{1}$} \\
\cline { 2 - 3 } Species & TRT $^{2}$ & CON \\
\hline Acinetobacter spp. & - & $1.09(1 / 92)$ \\
Actinobacillus spp. & - & $3.26(3 / 92)$ \\
Bacillus spp. & $7.69(2 / 26)$ & $9.78(9 / 92)$ \\
Staphylococcus spp. & $26.92(7 / 26)$ & $7.61(7 / 92)$ \\
Corynebacterium spp. & $23.08(6 / 26)$ & $4.35(4 / 92)$ \\
Escherichia coli spp. & $34.62(9 / 26)$ & $48.91(45 / 92)$ \\
Enterobacter spp. & - & $2.17(2 / 92)$ \\
Klebsiella spp. & - & $1.09(1 / 92)$ \\
Pasteurella spp. & $7.69(2 / 26)$ & $4.35(4 / 92)$ \\
Providencia spp. & - & $1.09(1 / 92)$ \\
Salmonella spp. & - & $2.17(2 / 92)$ \\
Streptococcus spp. & - & $14.13(13 / 92)$ \\
\hline
\end{tabular}

${ }^{1}$ From a total of 176 bacterial isolates obtained, 118 isolates $(67.04 \%)$ were identified and reported as a proportion (\%) over the total (n) number of isolates of 1 particular genus from the total (n) number of identified isolates obtained from the TRT (26) and CON (92) groups.

${ }^{2}$ Ten swabs samples from the TRT group yielded no bacteria growth (negative culture)
AI has not yet been reported, the bacteria may colonize the uterine lining and trigger an inflammatory response (postbreeding subclinical endometritis), as shown in mares (Katila et al., 1996; Maischberger et al., 2008), which may prevent the events leading to maternal recognition of pregnancy. Recognized uterine pathogens (Arcanobacterium pyogenes, Prevotella melaninogenica, E. coli, Fusobacterium necrophorum, and Proteus spp.), potential uterine pathogens (Bacillus spp. and Pasteurella spp.), and opportunistic uterine contaminants (Streptococcus spp., Providencia spp., Klebsiella spp., CNS, and Corynebacterium spp.) have been associated with uterine diseases (e.g., metritis, endometritis) and decreased fertility in dairy cattle (Sheldon et al., 2002; Williams et al., 2005, 2007). Furthermore, it has been shown that the presence of $E$. coli and A. pyogenes in the bovine uterus is associated with ovarian dysfunction (smaller follicle diameter and corpora lutea with lower plasma estradiol and progesterone; Williams et

Table 4. Pregnancies per AI (PAI) from lactating dairy cows that were inseminated with (TRT) and without (CON) the use of a protective plastic sheath (PS)

\begin{tabular}{llll}
\hline & \multicolumn{3}{c}{ PAI } \\
\cline { 2 - 4 } Item & TRT & CON & P-value \\
\hline Overall (\%) & $42.7^{\mathrm{a}}$ & $36.1^{\mathrm{b}}$ & 0.03 \\
First service (\%) & $43.8^{\mathrm{a}}$ & $43.01^{\mathrm{a}}$ & 0.87 \\
Second or greater services (\%) & $43.8^{\mathrm{a}}$ & $32.3^{\mathrm{b}}$ & 0.007 \\
\hline
\end{tabular}

${ }^{\mathrm{a}, \mathrm{b}}$ Values with different superscript letters within a row differ significantly at $P<0.05$.

${ }^{1}$ At the time of AI, 996 services (performed by the same AI technician) from lactating dairy cows were randomly assigned to 1 of the 2 treatment groups, with (TRT, $\mathrm{n}=487$ ) and without $(\mathrm{CON}, \mathrm{n}=509)$ the use of a protective PS. 
al., 2007). The prevalence of anaerobic bacteria (e.g., Prevotella spp., F. necrophorum, Fusobacterium nucleatum; Sheldon et al., 2009), mycoplasmas, and ureaplasmas (Doig et al., 1979; Mulira et al., 1992) were not investigated in this study; however, a real risk exists that these bacteria may reduce fertility in dairy cattle. The potential detrimental effects of introduced bacteria (e.g., from vaginal origin) into the uterine lumen at the time of AI need further investigation.

Reproductive outcomes (PAI) following the use of protective PS at the time of AI were assessed in this study. In the present study the proportion of PAI for first services were comparable to a similar reproductive protocol (Silva et al., 2009), and no difference was observed between cows inseminated with or without the use of PS. Further analysis revealed that PAI increased for the second or greater services in lactating dairy cows inseminated with the use of PS. Previous studies reported no improvement on conception to first services in dairy cattle (King et al., 1984; Richards et al., 1984) when using the same PS at the time of AI. These studies were carried out more than $20 \mathrm{yr}$ ago, using several AI technicians, and only nonreturn rates to first service were evaluated. In our study, all the AI were carried out by $1 \mathrm{AI}$ technician following the same reproductive program within 1 commercial dairy farm and similar distribution of services for both treatment groups (TRT and CON) with respect to parity (multiparous and primiparous), DIM, milk yield, and SCC at the closest DHIA test relative to AI.

It is well documented that fertility in high-producing dairy cows has decreased over the last decade (Lucy, 2001; Thatcher et al., 2006). Furthermore, lactating dairy cows have higher fertility to the first postpartum services as opposed to second or greater services (Silva et al., 2009). Multiple events such as difficult calving (Lombard et al., 2007), uterine diseases (e.g., metritis and endometritis; LeBlanc et al., 2002), and anovular cows at the time of the AI (Santos et al., 2009) have been associated with lower reproductive performance in dairy cattle. During AI, not only semen but also bacteria and debris can be introduced into the uterine lumen and lead to chronic inflammation and decreased fertility in mares (Maischberger et al., 2008). This physiological immune reaction, described as postmating inflammatory response (Zerbe, 2006; Schuberth et al., 2008), is cleared within $48 \mathrm{~h}$ under normal conditions (Katila et al., 1996). In lactating dairy cows, a higher proportion of PMN (>15\%) immediately before (Williams et al., $1988)$ and $4 \mathrm{~h}$ post-AI were associated with poor reproductive performance (Kaufmann et al., 2009). Estrogen has been shown to regulate leucocyte migration into the cervix, the uterus, and the extracellular matrix of the reproductive tract (Ramos et al., 2000; Stygar et al., 2006). Although hormone profile was not assessed in this study, reduced level of estradiol at the time of AI may lead to poor immunological response in the uterus (Lacetera et al., 2004; van Knegsel et al., 2007) and reduced fertility (Leroy et al., 2004). Therefore, lactating dairy cows may benefit from the use of protective PS at the time of AI, which can prevent the introduction of vaginal contaminants into the uterus, resulting in optimal uterine environment and improved PAI as observed for cows in the TRT group.

\section{CONCLUSIONS}

Results from this study suggest that the use of PS at the time of AI (clean AI technique) reduced contamination of the AIC and improved PAI for second or greater services in lactating dairy cows. Further investigation is needed under various reproductive management conditions to confirm and determine the underlying mechanisms for these findings, especially whether a correlation exists between the introduction of vaginal contaminants into the uterine lumen and the subsequent reproductive performance of lactating dairy cows (e.g., repeat breeders). Performing a clean AI technique through the use of PS may be an effective strategy to improve reproductive outcomes in dairy cattle.

\section{ACKNOWLEDGMENTS}

The authors thank the collaborating dairy farm and the staff for providing the animals used in this experiment. The authors also thank Coba/Select Sires Inc. (Columbus, $\mathrm{OH}$ ) for the donation of the protective AI plastic sheaths.

\section{REFERENCES}

Bar, D., Y. T. Gröhn, G. Bennett, R. N. González, J. A. Hertl, H. F. Schulte, L. W. Tauer, F. L. Welcome, and Y. H. Schukken. 2008. Effects of repeated episodes of generic clinical mastitis on mortality and live culling in dairy cows. J. Dairy Sci. 9:2205-2214.

Brusveen, D. J., A. P. Cunha, C. D. Silva, P. M. Cunha, R. A. Sterry, E. P. B. Silva, J. N. Guenther, and M. C. Wiltbank. 2008. Altering the time of the second gonadotropin-releasing hormone injection and artificial insemination (AI) during Ovsynch affects pregnancies per AI in lactating dairy cows. J. Dairy Sci. 91:1044-1052.

Caraviello, D. Z., K. A. Weigel, P. M. Fricke, M. C. Wiltbank, M. J. Florent, N. B. Cook, K. V. Nordlund, N. R. Zwald, and C. L. Rawson. 2006. Survey of management practices on reproductive performance of dairy cattle on large us commercial farms. J. Dairy Sci. 89:4723-4735.

Doig, P. A., H. L. Ruhnke, A. L. MacKay, and A. N. C. Palmer. 1979. Bovine granular vulvitis associated with ureaplasma infection. Can. Vet. J. 20:89-94.

Katila, T., M. Celebi, and E. Koskinen. 1996. Effect of timing of frozen semen insemination on pregnancy rate in mares. Acta Vet. Scand. 37:361-365.

Kaufmann, T. B., M. Drillich, B. A. Tenhagen, D. Forderung, and W. Heuwieser. 2009. Prevalence of bovine subclinical endometritis $4 \mathrm{~h}$ after insemination and its effects on first service conception rate. Theriogenology 71:385-391. 
King, G. J., D. J. Bellissimo, and W. J. Penner. 1984. Routine use of protective sheaths in cattle inseminations did not improve fertility. Can. Vet. J. 25:327-328.

Lacetera, N., D. Scalia, O. Franci, U. Bernabucci, B. Ronchi, and A. Nardone. 2004. Short communication: Effects of nonesterified fatty acids on lymphocyte function in dairy heifers. J. Dairy Sci. 87:1012-1014

LeBlanc, S. J., T. F. Duffield, K. E. Leslie, K. G. Bateman, G. P. Keefe, J. S. Walton, and W. H. Johnson. 2002. Defining and diagnosing postpartum clinical endometritis and its impact on reproductive performance in dairy cows. J. Dairy Sci. 85:2223-2236.

Leroy, J. L. M. R., T. Vanholder, J. R. Delanghe, G. Opsomer, A. Van Soom, P. E. J. Bols, J. Dewulf, and A. de Kruif. 2004. Metabolic changes in follicular fluid of the dominant follicle in high-yielding dairy cows early post partum. Theriogenology 62:1131-1143.

Lombard, J. E., F. B. Garry, S. M. Tomlinson, and L. P. Garber. 2007. Impacts of dystocia on health and survival of dairy calves. J. Dairy Sci. 90:1751-1760.

Lucy, M. C. 2001. Reproductive loss in high-producing dairy cattle: Where will it end? J. Dairy Sci. 84:1277-1293.

Maischberger, E., J. A. Irwin, S. D. Carrington, and V. E. Duggan. 2008. Equine post-breeding endometritis: A review. Ir. Vet. J. 61:163-168.

Mulira, G. L., J. R. Saunders, and A. D. Barth. 1992. Isolation of ureaplasma diversum and mycoplasmas from genital tracts of beef and dairy cattle in Saskatchewan. Can. Vet. J. 33:46-49.

NRC. 2001, Nutrient Requirements of Dairy Cattle. 7th rev. ed. National Academy Press, Washington, DC.

Pinedo, P. J., and A. De Vries. 2010. Effect of days to conception in the previous lactation on the risk of death and live culling around calving. J. Dairy Sci. 93:968-977.

Pursley, J. R., M. O. Mee, and M. C. Wiltbank. 1995. Synchronization of ovulation in dairy cows using PGF2[alpha] and GnRH. Theriogenology 44:915-923.

Ramos, J. G., J. Varayoud, L. Kass, H. Rodriguez, M. Munoz de Toro, G. S. Montes, and E. H. Luque. 2000. Oestrogen and progesterone modulation of eosinophilic infiltration of the rat uterine cervix. Steroids 65:409-414.

Richards, M. W., J. C. Spitzer, S. K. Newman, and C. E. Thompson. 1984. Bovine pregnancy and nonreturn rates following artificial insemination using a covered sheath. Theriogenology 21:949-957.

Santos, J. E. P., H. M. Rutigliano, and M. F. S. Filho. 2009. Risk factors for resumption of postpartum estrous cycles and embryonic survival in lactating dairy cows. Anim. Reprod. Sci. 110:207221.

SAS Institute Inc. 2009. SAS/STAT 9.2 User's Guide. 2nd ed. SAS Institute Inc., Cary, NC.

Schuberth, H. J., U. Taylor, H. Zerbe, D. Waberski, R. Hunter, and D. Rath. 2008. Immunological responses to semen in the female genital tract. Theriogenology 70:1174-1181.

Sheldon, I. M., D. Noakes, A. Rycroft, D. Pfeiffer, and H. Dobson. 2002. Influence of uterine bacterial contamination after parturition on ovarian dominant follicle selection and follicle growth and function in cattle. Reproduction 123:837-845.

Sheldon, I. M., J. Cronin, L. Goetze, G. Donofrio, and H. J. Schuberth. 2009. Defining postpartum uterine disease and the mechanisms of infection and immunity in the female reproductive tract in cattle. Biol. Reprod. 81:1025-1032.

Silva, E., R. A. Sterry, D. Kolb, N. Mathialagan, M. F. McGrath, J. M. Ballam, and P. M. Fricke. 2009. Effect of interval to resynchronization of ovulation on fertility of lactating Holstein cows when using transrectal ultrasonography or a pregnancy-associated glycoprotein enzyme-linked immunosorbent assay to diagnose pregnancy status. J. Dairy Sci. 92:3643-3650.

Stygar, D., P. Westlund, H. Eriksson, and L. Sahlin. 2006. Identification of wild type and variants of oestrogen receptors in polymorphonuclear and mononuclear leucocytes. Clin. Endocrinol. (Oxf.) 64:74-81.

Thatcher, W. W., T. R. Bilby, J. A. Bartolome, F. Silvestre, C. R. Staples, and J. E. P. Santos. 2006. Strategies for improving fertility in the modern dairy cow. Theriogenology 65:30-44.

Troedsson, M. H. T. 2006. Breeding-induced endometritis in mares. Vet. Clin. North Am. Equine Pract. 22:705-712.

Tsousis, G., R. Sharifi, and M. Hoedemaker. 2009. Associations between the clinical signs of chronic endometritis with ovarian cysts and body condition loss in German Holstein Friesian cows. J. Vet. Sci. 10:337-341.

USDA. 2009. Dairy 2007, Part IV: Reference of dairy cattle health and management practices in the United States, 2007. USDA, Washington, DC.

van Knegsel, A. T. M., G. de Vries Reilingh, S. Meulenberg, H. van den Brand, J. Dijkstra, B. Kemp, and H. K. Parmentier. 2007. Natural antibodies related to energy balance in early lactation dairy cows. J. Dairy Sci. 90:5490-5498.

Williams, B. L., P. L. Senger, L. R. Stephens, and A. C. Ward. 1988. Relationships between days post partum, observed estrus and uterine microflora in commercial dairy cows. Theriogenology 30:555561.

Williams, E. J., D. P. Fischer, D. E. Noakes, G. C. W. England, A. Rycroft, H. Dobson, and I. M. Sheldon. 2007. The relationship between uterine pathogen growth density and ovarian function in the postpartum dairy cow. Theriogenology 68:549-559.

Williams, E. J., D. P. Fischer, D. U. Pfeiffer, G. C. W. England, D. E. Noakes, H. Dobson, and I. M. Sheldon. 2005. Clinical evaluation of postpartum vaginal mucus reflects uterine bacterial infection and the immune response in cattle. Theriogenology 63:102-117.

Zerbe, H. 2006. Immunological response of the uterus to semen-Only a clearance mechanism? Reprod. Domest. Anim. 41(Suppl. 1):41. (Abstr.)

Zerbe, H., H. J. Schuberth, F. Engelke, J. Frank, E. Klug, and W. Leibold. 2003. Development and comparison of in vivo and in vitro models for endometritis in cows and mares. Theriogenology 60:209-223. 